\title{
Clinical Supervision for Quality Reproductive Health Services in Primary Health Care in Egypt: A Qualitative Analysis
}

\author{
Ghada Wahby, Madiha Said Abdel-Razik, Fayrouz El Egizy, Marwa Rashad Salem* \\ Department of Public Health and Community Medicine, Faculty of Medicine, Cairo University, Cairo, Egypt
}

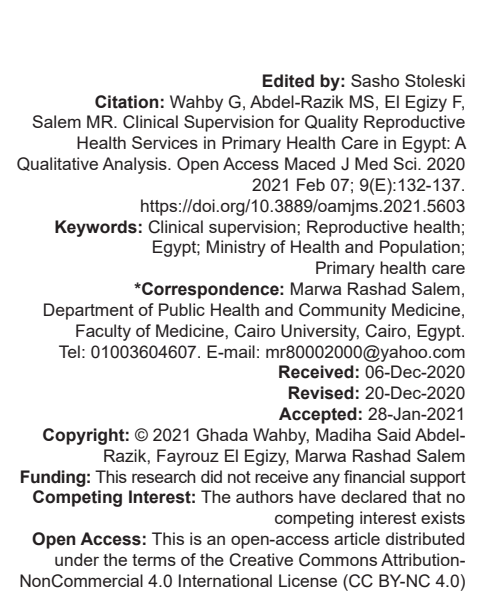

Introduction

Clinical supervision (CS) in primary health care $(\mathrm{PHC})$ is a formal, systematic, and continuous process of professional support and learning for service providers [1]. CS aims to assist in developing and upgrading the practices of service providers through regular support by experienced colleagues [2]. This process leads to increased skill and improved outcomes of client care [3].

A study conducted in Egypt by the National Population Council/Research Management Unit and Training and Research Center [4] showed that training alone could not produce sustained behavior change among service providers to have skills in counseling and intrauterine device insertion. Furthermore, the study shed the light on the importance of promoting the role of clinical supervisors in on-the-job training (OJT), especially in rural health units [4].

The Ministry of Health and Population (MOHP)/ head quarter considers that the role of clinical supervisor is essential for continuous medical education in RHS at the local level [5]. The adequate and satisfactory role of clinical supervisors is mandatory for continuous quality improvement of service delivery at the family planning/ reproductive health services (FP/RHS) clinic level. In addition, with the expansion of the health system reform and changes in the vertical program management system into technical departments that support the family medicine approach, the clinical supervisor's role should be strengthened to provide continuous technical/clinical support for the FP/RHS [6]. Therefore, the MOHP sector is in need for objective analysis-based information that could help setting strategies and plans to promote the role of CS in FP/RHS. Consequently, the researchers conducted the current study to identify the perspectives of the MOHP/FP-RHS central office (CO), governorates, districts, and service providers regarding strengths and shortcomings of the CS system.

\section{Methods}

\section{Study setting}

Three policy levels (MOHP/FP-RHS CO, health directorate, and districts) and health units in five governorates: Alexandria (Urban Governorate), Menofia and Sharkia (Lower Egypt Governorates), and Beni-Suef and Asuit (Upper Egypt Governorates). 


\section{Study design}

The current study is a health services research, objective evaluation study. It included focus group discussions - FGDs - with key persons at the three policy levels.

\section{Sample size and sampling technique}

The sampling technique is multistage random sampling. Total number of governorates in Egypt is 27. After the exclusion of frontier governorates (governorates which have limited number of health units), one urban governorate: Alexandria (8 districts and 147 units), two Lower Egypt governorates: Menoufia (10 districts and 251 units) and Sharkia (18 districts and 483 units), and two Upper Egypt governorates: BeniSuef ( 7 districts and 194 units) and Assiut (13 districts and 253 units) were selected. Twenty-five districts were randomly selected from the five governorates. In each governorate, the number of districts selected is proportionate to the total number of districts.

For qualitative data: The staff members working at the central, governorate, district, and health unit levels included in this study: From MOHPFP-RHS-CO: 25 central supervisors, governorates: 5 FP/RHS directors, 5 obstetrics and gynecology specialist clinical supervisors, and 5 nurse supervisors (governorate team supervisors) with 15 respondents, district team supervisors: Each team is composed of a FP/RHS district director, a clinical supervisor, and a nurse supervisor with a total number of 75 respondents. A total number of 21 FGDs were conducted: 3 FGDs for CO staff, 1 for governorate FP/RHS directors, 1 for governorate clinical supervisors, 1 for governorate nurse supervisors, 5 for district FP/RHS directors, 5 for district clinical supervisors, and 5 for district nurse supervisors.

\section{Data collection}

We developed FGDs guidelines for qualitative data collection. The FGDs were conducted at the PHC units. Before each FGD, the investigator led the discussion, introduced all participants, explained the general topics of discussion, and encouraged all participants to contribute their ideas. A trained notetaker assisted the investigator in recording the sessions using voice recorders as well as written notes. The reviewed recorded scripts are typed after each FGD.

\section{Statistical analysis}

Focus group discussion transcripts were reviewed, coded, and analyzed using classical content analysis with generation of matrices containing the most frequent responses under the relevant themes.

\section{Ethics approval and consent to take part}

A scientific committee headed by the planning and research unit director at the MOHP/FP-RHS CO, monitoring and evaluation unit director, and MOHP policy and research advisor reviewed and approved the research proposal, work plan, and data collection instruments. MOHP/FP-RHS-MIS staff members managed the process of data entry and quality check. Written informed consent of the respondents to participate in the study was obtained. The researchers conducted the study in accordance with the Declaration of Helsinki.

\section{Results}

The FGDs were conducted with the different categories in the MOHP/FP/RHS organizational levels (central, governorate, and district levels) and the qualitative data were used for objective analysis that reflects current situation.

The current role of the clinical supervisor versus the planned role

The MOHP/FP-RHS central office staff gave the history and the philosophy of having clinical supervisors in the supervision system. The staff personnel were working in the $\mathrm{CO}$ since the early nineties mentioned that the clinical supervisor is considered as the cornerstone of the supervision system. At the district level, the clinical supervisor is in a continuous contact with health services providers. They also said that the clinical supervisors are "our eyes on the service providers." The role of clinical supervisor in the continuous capacity building of individual service providers is essential and complementary to the regular training activities.

The set criteria to select clinical supervisors include: Being an obstetrics and gynecology specialist, working in a MOHP hospital at the governorate or district level, accepting to work as a part-timer in RHS supervision, and participating in the reporting process about quality improvement program (QIP) on a quarterly basis.

The MOHP-FP/RHS department established extensive training courses to the governorate supervision teams (21 days) who became trainers to the district supervision teams (14 days training course). The training includes supervision skills and QIP. Clinical supervisors were trained to be capable to conduct OJT for physicians and nurses in the PHC facilities and refer complicated $\mathrm{RH}$ cases to be managed at the hospital under his/her supervision.

The MOHP-FP/RHS department approach in capacity building of clinical supervisors was focused on 
mass training approach where all the supervision teams across the country were trained at the same time, and supervision system has operationalized across the country at the same time.

To support the CS role, there were specific polices that require that the recruited MOHP-FP/RHS department central office staff should be obstetrics and gynecology specialists to be counterparts to the clinical supervisors at the governorate and district levels.

\section{Strengths of the role of clinical supervisor in MOHP/FP-RHS}

Clinical supervisors proved their effectiveness in the FP-RHS program. They are considered as the important manpower resources who disseminate updated information about contraceptive technology and management of reproductive system infections among specialists in the hospitals as well as the FP/ RHS providers in $\mathrm{PHC}$ clinics.

"The clinical supervisor is a FP-RHS ambassador where he/she disseminates the updated information on contraceptive technology and combats rumors about FP among his/her colleagues in the hospital" Governorate FP/RHS director.

Although clinical supervisors have to conduct supervision to help, they sometimes provide FP/ RHS services as management of complicated cases in antenatal care and management of genital tract infections and infertility cases. FP/RHS directors at the governorate and district levels asserted that clinical supervisors are very supportive to the FP/RHS program.

"Sometimes, we depend on the clinical supervisor in the delivery of services. He/she provides FP-RHS in PHC facilities in case of absence of the physician" Governorate FP/RHS Director.

Furthermore, clinical supervisors play a major role in outreach $\mathrm{RH}$ services.

"The clinical supervisors work in the mobile clinics in the service-deprived areas as well as in the mobile teams" FP/RHS district director.

In addition, clinical supervisors have a very supportive role in RHS program in the areas with great needs for support in $\mathrm{RH}$ service delivery, that is, the rural health units. The role of clinical supervisors in the $\mathrm{RH}$ in $\mathrm{PHC}$ depends on the collaboration between $\mathrm{PHC}$ and secondary health care. Hospitals could manage reallocation of obstetrics and gynecology specialists to satisfy the needs of both hospitals and PHC facilities.

Clinical supervisors considered that working in the FP/RHS program provided them the opportunity to participate in many training programs. Such opportunity is missed for their colleagues working in the same hospital.

"Working as FP/RHS clinical supervisors gave us the opportunity to be trained in contraceptive technology, Sonar, and others" A Governorate Clinical Supervisor.

\section{Challenges for the effectiveness of clinical supervisors in FP/RHS program}

Due to the deep involvement of the central office staff in managerial issues and the added new programs and projects, the role of $\mathrm{CO}$ staff in supporting the clinical supervisors became limited.

"Clinical supervisors were technically supportive at the MOHP central level. However, the deep involvement of the central office staff in managerial issues resulted in marked reduction in this role" MOHP/ CO staff.

The barriers for the supervision system have been reflected on the clinical supervisor's role. The supervision teams at the governorate and district levels have their FP/RHS director acting as a team leader who is heavily involved in many projects. In addition, the less motivation of the part-time clinical supervisors had resulted in reluctance in the supervision process. One of the MOHP/FP-RHS staffs said that sometimes the nurse supervisor conducts the supervision visit alone.

Furthermore, the high turnover of trained clinical supervisors and the inability of the training program to cover the new clinical supervisors with appropriate training courses as supervision management and technical skills in FP/RHS had resulted in involvement of untrained clinical supervisors in the supervision process.

The frequently raised problems related to lack of resources, depreciation of FP-RHS clinics, and other issues related to the work environment were not given priority to be solved at any level. Consequently, the technical issues related to clinical supervisors' performance could be negatively affected.

Most of the participants of CO staff, FP/RHS directors, and nurse supervisors at the governorate and district levels had affirmed that having the clinical supervisors as part-timers have limited their opportunity for investing their experience in FP/RHS supervision system. However, clinical supervisors consider the dual job gives them an opportunity for continuous medical education due affiliation to the hospital. In addition, affiliation to the FP/RHS program gives the opportunity of transferring experience to service providers in $\mathrm{PHC}$.

"The Clinical Supervisor is part-timer in FP/RHS, consequently, he/she cannot devote enough time to FP/ RHS in the PHC facilities" Governorate FP Director.

\section{Teamwork}

Clinical supervisors provide technical assistance to both nurses and physicians, especially in the areas of reproductive tract infection management and infection control. However, some of the nurse 
supervisors consider that both nurse supervisors and clinical supervisors provide information to the same nurse about the infection control which could result in an overlap for the roles.

The composition of supervision team of FP/ RHS director, nurse supervisor, and clinical supervisor could confront problems such as arranging scheduled visits that fit all team members, especially the clinical supervisor.

"Sometimes, the FP/RHS director says that either to come with me to this supervision visit or you are going to be deprived from the financial incentive of the visit" District clinical supervisors.

\section{Preparation}

The clinical supervisors demand was capacity building for continuous improvement of the OJT quality. However, the planned training program does not with this objective. Clinical supervisors believe that program managers provide much support to the FP/RHS director than to clinical supervisors where FP/RHS directors sometimes participate in training courses related to the clinical supervisor responsibilities.

"Sometimes, the FP/RHS director is selected to participate in a highly technical training course as 'Implanon' insertion, with no opportunities for clinical supervisors to participate in such specialized course" Governorate Clinical supervisor.

At the same time, clinical supervisors could be selected to participate in training courses which are not related to $\mathrm{FP} / \mathrm{RHS}$ at $\mathrm{PHC}$ level.

"Sometimes, they send clinical supervisors to be trained in specific topics as management of menopause and early detection of cancer. FP/RHS service providers won't benefit from such type of capacity building. It has nothing to do with OJT in FP/ RHS" Governorate Clinical Supervisors.

In addition, clinical supervisors are trained with other team members in supervision management, with less opportunity for capacity building to have skills to be a trainer for the OJT. What is the need for the word "capacity building" here? Meaning is understood without it, you can explain in Arabic to check.

"One of the major defects in preparing a clinical supervisor is that we train hem/her in supervision management/tasks and not on how to be trainer while doing OJT" MOHP/FP/RHS-CO staff members.

\section{Management}

Clinical supervisors think that they have less authority to facilitate problem-solving and decisionmaking. They feel that they give "incomplete help" to service providers. They also feel dissatisfied as FP/ RHS directors consider that the clinical supervisors job is "just conduction of the supervision visits" with less interest for his/her being partner in decision-making.

"We do not get enough support, we do not have enough authorities or have a strong role in decision making - the FP/RHS department want me to carry out the supervision visit - without contributing in decision making" Governorate Clinical Supervisor.

Clinical supervisors feel that their role ends at the governorate level. They do not have counterpart clinical supervisor at the central level to discuss different issues derived from the field visits.

"There is no direct link between the clinical supervisors in the governorates and the MOHP/FP/ RHS central office staff. The clinical supervisor's role ends at the governorate level" Governorate Clinical Supervisor.

\section{Motivation}

Clinical supervisors at all levels have expressed their dissatisfaction because of the less moral motive especially that they are not invited to attend the meetings at the central level. This dissatisfaction is also attributed to their limited opportunities to be partners in decision making, especially in the issues related to service providers. Moreover, the financial motive for this role is not encouraging because it is not allowed for the clinical supervisor to combine between two types of incentives, that is, the incentive from FP/RHS program and that from the hospital according to law.

"The exclusion of clinical supervisors from being partners in decision-making, especially with the issues deeply linked with his role in the FP/RHS program: The selection of service providers to participate in the training programs is unfair and depressing" Governorate clinical supervisor.

\section{Sustainability}

There were many questions which had been raised by the interviewed supervision teams which are related to the role of clinical supervisors in governorates in which health reform is operating and the FP/RHS clinic was merged with the family medicine one. It is revealed from the answers that clinical supervisors cannot follow the same standards set by the MOHP/FP/RHS where the family medicine follows different standards related to FP/RHS service delivery. However, there is no clear vision, even at the central level, regarding the role of FP/ RHS clinical supervisor in the family medicine program.

\section{Suggestions to promote the effectiveness} of the CS in the quality FP/RHS services

Most of the FGDs participants emphasized that more support and motivation is needed to invest 
the CS system in FP/RHS program for sustainable improvement. Annual meetings and conferences would allow good communication for clinical supervisors at all levels and exchanging experiences. The conferences could provide good opportunity to revise and discuss scientific papers as well as update knowledge in FP/ RHS.

"The annual conference with participation of all clinical supervisors at all levels is the best approach to motivate them for sustainable improvement in performance" MOHP/Central Office Staff members.

Expanding the communication circle of the clinical supervisor is essential. The FGDs participants suggested more participation of the clinical supervisor in the monthly meetings of the health district staff and those with the health directorate director.

"Involvement of clinical supervisors in the decision making process at the governorate level, through participation in monthly meetings, and more communication with the Health Directorate Director."

\section{Discussion}

The current study presents objective analysis to MOHP-FP/RHS CS. The study used qualitative data to cover different aspects of CS and at all levels. This topic is important for policy and programmatic stockholders to abstract learned lessons from such study methods and analysis of findings.

There is an evidence that CS conducted by clinical medical professionals is associated with a significant improvement in the performance of service providers with positive impact on utilizers of health services [7], [8]. The current study described the MOHP CS system, which is characterized by being reflective supervision. Such a system depends on direct observation of the supervisors to SP during service delivery in the workplace [5]. SP are exposed to CS from different levels: Central, directorate, and district levels. Each level could augment SP knowledge and skills in FP/RHS. The study reflected the empowered role of MOHP to develop self-dependent CS system. The clinical supervisor came from the secondary level of care /MOHP hospitals to work with the PHC sector with supportive involvement in FP/RHS program. Other CS systems depend on external clinical supervisors who work as teachers in medical and nursing schools to supervise performance of the service providers. Buscari et al. in 2005 stated that the direct supervision is an effective tool in facilitating the performance and feedback of the supervised needs, which is a vital element of efficient CS [9], [10]. Such a situation reveals autonomy/self-dependence and empowerment within MOHP to institutionalize CS system at all its levels to support FP/RHS. Joining between primary, that is, PHC SP and secondary level of care, that is, gynecology specialists working in MOHP hospitals is an achievement for integration of FP/RHS across the levels of health care [11], [12]. Obstetrics and gynecology $(O \& G)$ specialists are involved in specific programs as QIP which include tasks out of their scope as O\&G specialists, as FP/RHS clinic infrastructure and operations especially recording system, infection control, presence of adequate medical supplies, etc. This issue circulates the concepts and elements of quality in primary and secondary health care considering that the main target is the effectiveness of care, improvements quality measures, and associated improved patient outcomes [13], [14]. The team of supervisors: FP/RHS director, gynecologist, and nurse represent comprehensive approach in CS. CS involves administrative policies, services, quality, job description, vertical and horizontal communication, and medical component of providing knowledge and specific practical skills, and practical case studies and management. Such types of CS teams were supported in different studies [14], [15], [16].

The accomplishment of MOHP of specific steps to build up CS, prepare service providers through preservice training and introducing them to the workplace, and served community was pivotal. This preparatory phase is illustrated in different studies as, for example, Martino et al. in 2006 who outlined the pathway for CS and developed a tool for its implementation [17]. Continuous communication between the health system and service providers is obvious through training courses, documents, and meetings with the district director. Similar to other forms of health professional education, it should include workshops and clinical rounds to ensure that CS has a greater impact on process of care [18].

Continuing medical education through OJT was one of the motives for service providers [19]. However, the current study raised the issue that service providers suggested more visits of CS, strengthening the role in solving problems in the workplace as increasing supplies from medications and contraceptive methods to health facilities.

The clinical supervisor solves operational problems related to shortage in the number of physicians to cover PHC facilities. To ensure sustainability of FP/ RHS, CS contributes in mobile clinic services that provide quality services to service deprived areas. Mobile clinics in Egypt supported FP/RHS through improving accessibility of clients in remote areas [5], [12].

The MOHP/FP/RHS clinical supervisors raised challenges for CS system. High population growth in Egypt population, expanding number of health units, and shortage in a number of service providers [6] and having high turnover rate among clinical supervisors reduce the efficiency and effectiveness of CS to PHC service providers. 


\section{Conclusion}

MOHP has a team-based CS system characterized by integrating primary and secondary levels of care to support quality FP/RHS programs and performance of $\mathrm{PHC}$ service providers.

\section{Acknowledgments} participant.

The researchers would like to thank the study

\section{References}

1. Milne DL, Watkins CE. Defining and understanding clinical supervision. In: The Wiley International Handbook of Clinical Supervision. New York: John Wiley and Sons; 2014. p. 1-19. https://doi.org/10.1002/9781118846360.ch1

2. Dilworth S, Higgins I, Parker V, Kelly B, Turner J. Examining clinical supervision as a mechanism for changes in practice: $\mathrm{A}$ research protocol. J Adv Nurs. 2013;70(2):421-30. https://doi. org/10.1111/jan. 12211

PMid:23865463

3. Haines A, Horton R, Bhutta Z. Primary health care comes of age looking forward to the $30^{\text {th }}$ anniversary of AlmaAta: Call for papers. Lancet. 2007;370:911-3. https://doi.org/10.1016/ s0140-6736(07)61423-8

PMid:17869618

4. Kemer G, Pope AL, Colburn AA. Expert site supervisors cognitions when working with counselor trainees. Clin Supervisor. 2017;36(2):241-58. https://doi.org/10.1080/073252 23.2017.1305937

5. Central Department of Technical Support and Projects. MOHP: 2 Version, Strategies Future and Analysis Sector Health Egypt: MOHP-Central department of Technical Support and Projects; 2003.

6. Health Information Office HIO-MOHP Annual Reports: 2005-2018.

7. Snowdon DA, Leggat SG, Taylor NF. Does clinical supervision of healthcare professionals improve effectiveness of care and patient experience? A systematic review. BMC Health Serv Res. 2017;17(1):786. https://doi.org/10.1186/s12913-017-2739-5 PMid:29183314

8. Kilminster SM, Jolly BC. Effective supervision in clinical practice settings: A literature review. Med Educ. 2000;34(10):827-40. https://doi.org/10.1046/j.1365-2923.2000.00758.x PMid:11012933
9. Snowdon DA, Hau R, Leggat SG, Taylor NF. Does clinical supervision of health professionals improve patient safety? A systematic review and meta-analysis. Int J Qual Health Care. 2016;28(4):447-55. https://doi.org/10.1093/intqhc/mzw059 PMid:27283436

10. Buscari JO, Weggelaar NM, Knottnerus AC, Greidanus PM, Scherpbier AJ. How medical residents perceive the quality of supervision provided by attending doctors in the clinical setting. Med Educ. 2005;39(7):696-703. https://doi. org/10.1111/j.1365-2929.2005.02190.x PMid:15960790

11. Abdel-Razik MS, Abdel-Hai R, Ibrahim H Causes of decrease in contraception Coverage Rate in Egypt 2002-2007. National Population Council; 2008.

12. Family Health Facility Implementation Manual. MOHP and Central Department for Technical Support and Projects. Quality Improvement and Accreditation Program, Version 2. Ch. 5. Family Health Facility Implementation Manual; 2004.

13. Gupta S, Moosa D, Macpherson A, Allen C, Tamari IE. Effects of a 12-month multi-faceted mentoring intervention on knowledge, quality and usage of spirometry in primary care: A beforeand-after study. BMC Pulm Med. 2016;16(1):56. https://doi. org/10.1186/s12890-016-0220-6

PMid:27103316

14. Brook RH, McGlynn EA, Shekelle PG. Defining and measuring quality of care: A perspective from US researchers. Int J Qual Health Care. 2000;12(4):281-95. https://doi.org/10.1093/ intghc/12.4.281

PMid:10985266

15. Eddy K, Jordan Z, Stephenson M. Health professionals experience of teamwork education in acute hospital settings: A systematic review of qualitative literature. JBI Database System Rev Implement Rep. 2016;14(4):96-137. https://doi. org/10.11124/jbisrir-2016-1843

PMid:27532314

16. Martino S, Paris M Jr., Añez L, Nich C, Canning-Ball M, Hunkele $\mathrm{K}$, et al. The effectiveness and cost of clinical supervision for motivational interviewing: A randomized controlled trial J Subst Abuse Treat. 2016;68:11-23. https://doi. org/10.1016/j.jsat.2016.04.005

PMid:27431042

17. Martino S, Ball SA, Gallon SL, Hall D, Garcia M, Ceperich S, et al. Motivational Interviewing Assessment: Supervisory Tools for Enhancing Proficiency. Salem, OR: Northwest Frontier Addiction Technology Transfer Center, Oregon Health and Science University; 2006.

18. Davis $D$, O'brien MA, Freemantle N, Wolf FM, Mazmanian $P$, Taylor-Vaisey A. Impact of formal continuing medical education: Do conferences, workshops rounds and other traditional continuing education activities change physician behavior or health care outcomes? JAMA. 1999;282(9):867-74. https://doi. org/10.1001/jama.282.9.867

PMid:10478694

19. Snowdon DA, Millard G, Taylor NF. Effectiveness of clinical supervision of allied health professionals: A survey. J Allied Health. 2016;45(2):113-12.

PMid:27262469 